\title{
Spectral measurements over test site Novi Iskar for creating a specific data base
}

Denitsa Borisova, Valentina Hristova, Ventzeslav Dimitrov, Hristo Nikolov, Margarita Goranova

Denitsa Borisova, Valentina Hristova, Ventzeslav Dimitrov, Hristo Nikolov, Margarita Goranova, "Spectral measurements over test site Novi Iskar for creating a specific data base," Proc. SPIE 11524, Eighth International Conference on Remote Sensing and Geoinformation of the Environment (RSCy2020), 115240E (26 August 2020); doi: 10.1117/12.2570741

SPIE Event: Eighth International Conference on Remote Sensing and Geoinformation of the Environment (RSCy2020), 2020, Paphos, Cyprus 


\title{
Spectral measurements over test site "Novi Iskar" for creating a specific data base
}

\author{
Denitsa Borisova $^{{ }^{\mathrm{a}} \mathrm{a}}$, Valentina Hristova ${ }^{{ }^{\mathrm{a}, \mathrm{b}} \mathrm{b}}$, Ventzeslav Dimitrov ${ }^{\mathrm{a}}$, \\ Hristo Nikolov ${ }^{\mathrm{a}}$, Margarita Goranova ${ }^{\mathrm{a}}$ \\ ${ }^{a}$ Space Research and Technology Institute - Bulgarian Academy of Sciences /SRTI-BAS/, \\ Acad. G. Bonchev Str., bl.1, Sofia 1113, Bulgaria \\ ${ }^{b}$ Dept. of Electrical Engineering and Physics, "Todor Kableshkov" University of Transport, \\ Geo Milev Str. 158, Sofia 1574, Bulgaria
}

\begin{abstract}
The authors aim to present the collecting of in-situ spectral data for filling in a thematic database of Earth observation as a part of joint project. In-situ spectrometric measurements were made for acquiring spectral data of the rock samples during and after a field campaign in the selected test site. The selected test points are around the town of Novi Iskar where space test site "Novi Iskar" is established. The related land covers in the studied area will also be taken into account in the analysis of satellite images of the region. These in-situ measurements are part of an integrated system for remote sensing and ground-based observations and in line with Copernicus In-Situ Component. In-situ spectrometric measurements have potential for long-term practical application to verify data, which increases their accuracy. Filling in the thematic database for monitoring over test site with the collecting spectral and ancillary data leads to an optimal correlation between the different methods of studying the different types of land covers, increases the effectiveness of scientific investigations in the field of Earth remote sensing, creates synergy between different scientific fields and helps to share information between researchers from different areas of scientific and practical interest. The team is developing a data base structure which is going to be available through SRTI-BAS website. The data base is going to include information about specific spectral properties of the studied objects in the test site. This work is supported by "National Science Fund" in Bulgaria under Contract number KP-06-M27/2.
\end{abstract}

Keywords: Earth Observations, remote sensing, spectral data, database

\section{INTRODUCTION}

In this work a project for the implementation of remote sensing research activities for the acquisition of new knowledge is described. The team of PhD students and Post-docs has an aim to collect spectral data for filling in thematic database in a selected test region. The first task is the selection of the proper methodology of acquiring in-situ spectral data of land covers in test site. The chosen methodology includes the following steps:

1) collecting samples and additional information;

2) laboratory and field spectrometric measurements;

3) spectral data verification.

For the implementation of these steps the test region ${ }^{1}$ has to meet the following requirements:

i) offers a wide variety of objects from the adopted nomenclature;

ii) has spectral data from Earth Observation device systems;

iii) has the possibility to perform regular measurements with available spectrometric systems.

For the purpose of this work the test region around the town of Novi Iskar which is one of the 24 municipalities of Sofia City Municipality covering $102.786 \mathrm{~km}^{2}$ is selected. First of the reasons to select this test site is the presence of 12 classes of land covers according CORINE was verified ${ }^{2}$.

*dborisova@stil.bas.bg; astronomer@abv.bg

8th International Conference on Remote Sensing and Geoinformation of the Environment, edited by

K. Themistocleous, et al. Proc. of SPIE Vol. 11524, 115241N · C The Authors. Published under a

Creative Commons Attribution CC-BY 3.0 License · doi: 10.1117/12.2570741 
This will allow the data received in the experiments to be considered reliable and representative and also be interpolated for larger areas with similar land covers. In this way, it will be possible to trace the dynamics of objects using data from spectrometric measurements. The second reason is the newest one established test site Novi Iskar where the additional data for verification in satellite data interpretation is needed ${ }^{1}$.

The obtained spectral data are result of performed laboratory and terrain spectrometric measurements of the presented in the test region land covers (minerals, rocks, soils, vegetation, etc.). Laboratory and terrain spectrometric measurements have been continuing for more than 30 years performed by different teams from SRTI-BAS. The authors of this study and together with their colleagues from RSS Dept. have a long term experience in the acquiring of spectral data from previous own experiments ${ }^{3-14}$. It is consisting of spectral data with the metadata and additional information for better interpretation of spacecraft images with different spatial resolution.

In this paper as an example the reflectance spectra of representative samples of rock and soil types from the test region are studied. This study propose that collected spectral data from terrain (field) spectrometric measurements of different rock and soil types and from laboratory spectrometric measurements of the samples collected during the same field campaign will be used for filling in the thematic spectral database. Based on the specific of the researched object the thematically oriented spectral databases begin to create ${ }^{15,16}$. For easy access to the spectral database without specialized programs, simple text versions of the spectral data, their visualizations, and text files in HyperText Markup Language (HTML) format with the metadata and additional information are planned to use. The authors aimed to offer the possibility for using of the spectral data from specialists working in different research and applied sciences following the procedures for accessing the thematic spectral database and downloading the spectral data.

The result of the project work is the collection of remote sensing data together with the additional information for filling in the thematic spectral database in remote sensing monitoring of the land covers in Novi Iskar region, Sofia, Bulgaria. The project also will contribute to enhancing the qualifications of the team members and to disseminating the new scientific knowledge to the scientific community. Therefore the results will increase efficiency of research investigations in remote sensing monitoring of land covers, synergy between different fields of science and practice, and shared information between researchers. The team is developing a data base structure which is going to be available through SRTI-BAS website. The data base is going to include information about specific spectral properties of the studied objects in the test site.

\section{MATERIALS AND METHODS}

The described below information for filling in the thematic spectral database are planned to use. The information should include description of: 1 - the selected test region; 2 - the studied objects in the selected region; 3 - laboratory and terrain (field) spectrometric instruments and remote sensing systems; 4 - laboratory and field spectrometric measurements; 5 database structure.

\subsection{Test region description}

The test region is around the town of Novi Iskar is one of the 24 municipalities of Sofia City Municipality, covering $102.786 \mathrm{~km}^{2}$. The test site Novi Iskar is located in the northwest part of the Metropolitan Municipality. For the territory of the Novi Iskar District, a geodatabase is composed, including satellite images and aerial photos for various temporal stages, digital elevation model and its derivatives, as well as vector information for relief, administrative boundaries, land cover and land use, soils, hydrographic network, transport infrastructure etc. The composed geodatabase for the Novi Iskar Town includes topographic maps and satellite images with medium and high resolution, digital terrain model, vector information for soil, land cover, land use, buildings and road infrastructure, climate data, etc.

For defining of test areas are used composite satellite images from Sentinel 2 multispectral instrument (MSI) in different years and seasons: 27.08.2017 (Figure 1a) in summer and 26.10.2019 (Figure 1b) in autumn. For precision and accuracy is used orthogonalization of satellite images of the test areas which is based on the three components: brightness, greenness and wetness ${ }^{17}$. Preprocessing is done in terms to receive the reflectance. After this, on the defined test areas, spectral reflectance characteristics of different land cover area - forest, grassland, water (Figure 1c), embedded rock type (rock sample) and bare soil (Figure 1d) are done ${ }^{18}$ in different years and seasons.

The database for the test site Novi Iskar could be upgrade with the spectral data obtained from the present measurements. The thematically distributed database will be supplemented with parallel information for terrestrial objects to provide for more precise interpretation of remote sensing data measurements. 


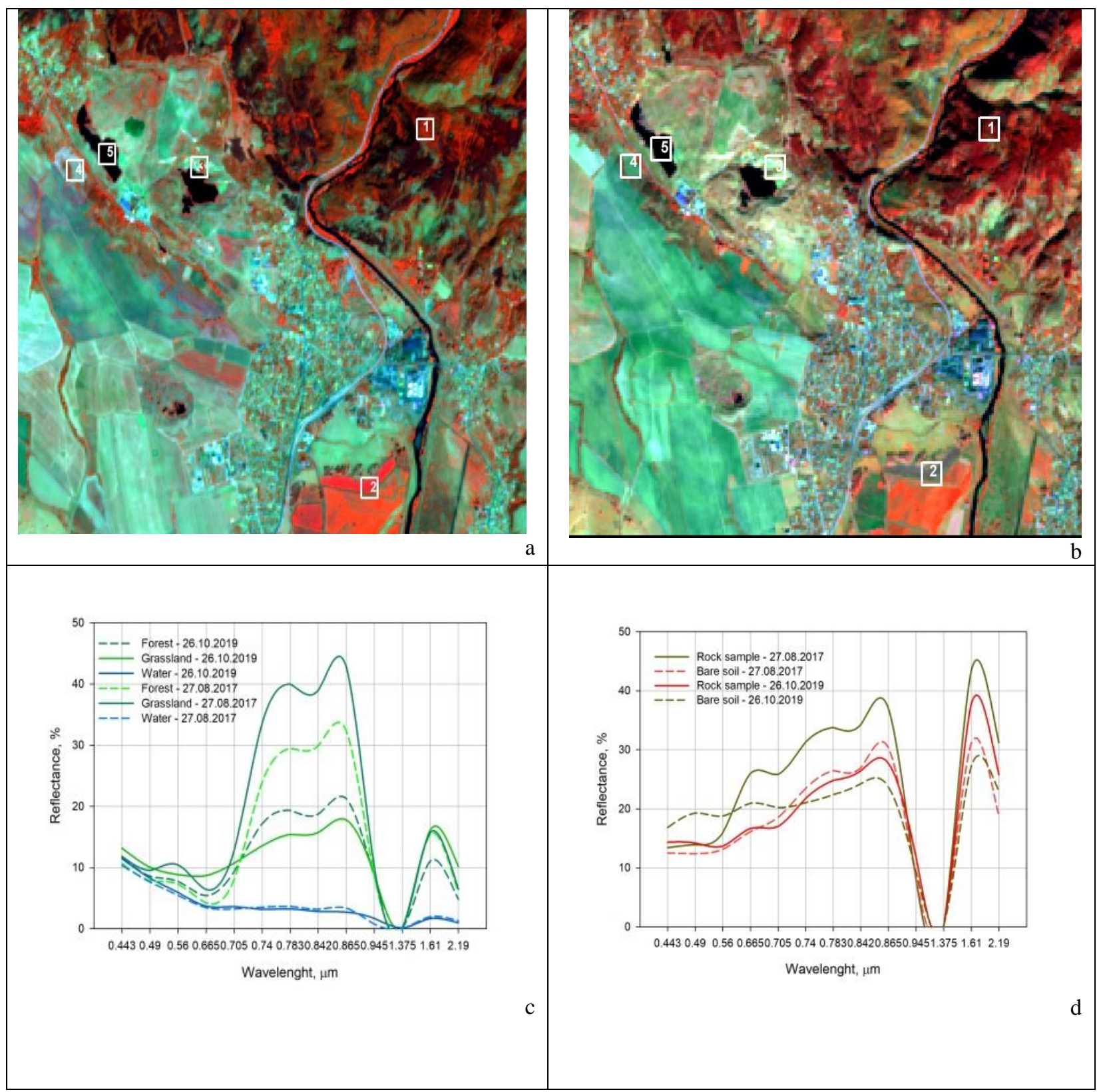

Figure 1. Test areas from Sentinel-2 and spectral reflectances

a) Composite satellite image Sentinel 2 MSI from 27.08.2017;

b) Composite satellite image Sentinel 2 MSI from 26.10.2019;

c) Spectral reflectance - test areas 1,2,5;

d) Spectral reflectance - test areas 3, 4.

\subsection{Short petrographic and soil description}

North of the town of Novi Iskar on the way to Mezdra outcrop of the Permian clastic depositions are embedded in rocks of Diabase-Phylitoid Complex, Balkan granitoids, Ordovician and Silurian rocks. The conglomerates composition of Berimerska and Kurilska group is polygenetic with various rock pieces of diabases, granodiorites, gneisses, etc. ${ }^{19}$ The studied rock types in the selected region are diabases and granodiorites. The analysis of the soil samples from the region shows deluvial and eutric soils. 


\subsection{Laboratory and field instruments and systems}

The in-situ (laboratory and terrain) spectral measurements of rock and soil samples are performed using laboratory and field spectrometers. The used remote sensing spectrometric system works in the wavelengths covering the spectral ranges from the visible /VIS/ to the near infrared /NIR/. A Thematically oriented multichannel spectrometer /TOMS/ is used to measure spectra included in the database. TOMS system is assembled in Remote Sensing System Department at Space Research and Technology Institute - Bulgarian Academy of Sciences in collaboration with Alabama State University USA ${ }^{20,21}$. TOMS covers the spectral range 0.4 to 0.9 microns and based on the one of the models of Ocean Optics Inc. Spectrometric measurements of representative samples of rocks and soils from Novi Iskar test region are made in laboratory and field conditions. Both type of in-situ measurements are performed using TOMS system.

In the thematic spectral database each spectral characteristic has also metadata, associated with the obtained spectrum. The metadata describe what was measured and can include details for the measurements were made and other supporting information about the nature and composition of the studied object.

\subsection{Laboratory and terrain spectrometric measurements}

The data from the laboratory and terrain spectrometric measurements in the test region in Stara Planina Mountain in Bulgaria are collected and with the related additional information are recorded as text files for filling in thematic database. As a result of these measurements spectral signatures of the investigated rock types of diabases and granodiorites and deluvial and eutric soils are acquired. The obtained data are processed statistically, and in the company software used on the spectrometer is set the registration of 100 spectra and their averaging.

\subsection{Database structure}

The structure of the database will include spectral measurement data with metadata and additional information recorded as text and graphic files.

The examples corresponding to spectral reflectance characteristics of different land cover area - forest, grassland, water (Figure 1c) could be presented in .csv file as follows in Table 1.

Table 1. Spectral reflectance characteristics of different land cover area - forest, grassland, water.

\begin{tabular}{|c|c|c|c|c|c|c|}
\hline Spectral reflectance, & $\begin{array}{c}\text { forest, } \\
\text { 27.08.2017 }\end{array}$ & $\begin{array}{l}\text { grassland, } \\
\mathbf{2 7 . 0 8 . 2 0 1 7}\end{array}$ & $\begin{array}{c}\text { water, } \\
27.08 . \\
2017\end{array}$ & $\begin{array}{c}\text { forest, } \\
26.10 .2019\end{array}$ & $\begin{array}{l}\text { grassland, } \\
\mathbf{2 6 . 1 0 . 2 0 1 9}\end{array}$ & $\begin{array}{c}\text { water, } \\
26.10 . \\
2019\end{array}$ \\
\hline 0,443 & 11,7 & 13,18 & 11,47 & 10,67 & 11,83 & 10,34 \\
\hline 0,49 & 8,57 & 10,05 & 8,27 & 7,85 & 9,55 & 7,63 \\
\hline 0,56 & 7,71 & 8,84 & 5,92 & 7,22 & 10,41 & 5,45 \\
\hline 0,665 & 5,41 & 8,69 & 3,69 & 4,23 & 6,42 & 3,44 \\
\hline 0,705 & 9,33 & 10,72 & 3,6 & 8,03 & 12,81 & 3,24 \\
\hline 0,74 & 17,14 & 13,54 & 3,17 & 23,91 & 33,58 & 3,51 \\
\hline 0,783 & 19,33 & 15,42 & 3,25 & 29,46 & 39,99 & 3,65 \\
\hline 0,842 & 18,76 & 15,75 & 2,84 & 29,94 & 38,98 & 3,2 \\
\hline 0,865 & 21,27 & $\begin{array}{ll}17,77 \\
\end{array}$ & 2,72 & 32,42 & 42,85 & 3,37 \\
\hline 0,945 & 8,62 & 8,85 & 1,69 & 8,74 & 10,13 & 0,76 \\
\hline 1,375 & 0,15 & 0,16 & 0,16 & 0,1 & 0,11 & 0,06 \\
\hline 1,61 & 11,08 & 16,2 & 1,68 & 15,41 & 15,74 & 1,97 \\
\hline 2,19 & 4,81 & 10,2 & 0,97 & 6 & 6,48 & 1,3 \\
\hline
\end{tabular}


The spectral library is going to be presented online, as .csv file in which all the required data is going to be presented. The license is going to be the Open Database License (ODbL). It is a license agreement intended to allow users to freely share, modify, and use this Database while maintaining this same freedom for others. Many databases are covered by copyright, and therefore this document licenses these rights. Some jurisdictions, mainly in the European Union, have specific rights that cover databases, and so the ODbL addresses these rights, too. Finally, the ODbL is also an agreement in contract for users of this Database to act in certain ways in return for accessing this Database ${ }^{22}$.

\section{RESULTS AND DISCUSSION}

\subsection{Specific data base}

The specific data base, also called spectral library, is going to be published online and is going to be public and free. Data will help you explain (both good and bad) decisions to your stakeholders. Along with accessing the resources around you, there are external tools that offer data collection, management, and analysis capabilities. It is going to be easy to analyze data, create data visualizations, or just boost your data literacy skills, as this public data set is a perfect place.

Another specific data is going to be about rocks and vegetation and their characteristic issues. The rock type, density, magnetic susceptibility, gamma radiation, mineral content, chemical composition, and their spectral signature are going to be included.

The dataset could contain a regional VIS-NIR $(350-2500 \mathrm{~nm})$ soil spectral library of the region. It may include metadata regarding the soils sampled. The records in the .csv file is going to relate on soils key properties as soil type, determination of soil organic carbon, organic matter, calcium carbonate, clay fraction, silt fraction, sand fraction, soil $\mathrm{PH}$, cation-exchange capacity, texture, and their spectral signature.

\subsection{Spectral data}

In the thematic database the spectral data from each measurement of the rock samples of diabases and granodiorites and of the deluvial and eutric soils are recorded as text files for further analyzing, interpreting and sharing. The results of the performed laboratory and terrain spectrometric measurements are visualized as plots of spectra.

\subsection{Metadata}

These types of data include information for each measurement: Dark Spectrum, Reference Spectrum, Number of Sampled Component Spectra, Integration Time, Spectra Averaged, and Correct for Electrical Dark, Number of Pixels in Processed Spectrum, etc. The description of each studied object - diabase, granodiorite, deluvial and eutric soils - is also included. For example, petrographic description of each rock sample, chemical composition of minerals, clay fraction, silt fraction, etc.

\subsection{Additional information}

The atmospheric and weather conditions in the time of the field measurements, GPS-coordinates of the point of measurements, photographs of the studied objects also would be added in specific thematic database.

\section{CONCLUSIONS}

The most important result of the presented work is the collection of the spectral data for filling in the specialized thematic database and the possibility of adding information from existing open access databases and repositories. These laboratory and field measurements are part of an integrated system for remote sensing and ground-based observations. Field or terrain spectrometric measurements have potential for long-term practical application when used to verify data, which increases their accuracy. This leads to an optimal correlation between the different methods of measuring and observing the different types of land covers, increases the effectiveness of scientific investigations in the field of remote sensing of the Earth's surface, creates synergy between different scientific fields and helps to share information between researchers from different areas of scientific and practical interest.

In this work are shown several examples. Spectral library can be fulfilled for different types of land cover for different time intervals using time series of satellite images. 
The next step of the presented work involves the creation of benchmarked experimental data sets with a defined metric that will allow direct comparability of data from various sources including from available spectral database such as the USGS Spectral Library, SPECCHIO, and others that researchers from the team use intensively in its work.

\section{ACKNOWLEDGEMENTS}

This work is supported by "National Science Fund” in Bulgaria under Contract number KP-06-M27/2.

\section{REFERENCES}

[1] Kancheva, R., Borisova, D., Georgiev, G. and Tishchenko, Yu., "Test-sites in remote sensing studies and Earth observations," Proceedings of International Conference "Fundamental Space Research 2009" Sunny Beach Bulgaria, 26-29 (2009).

[2] Stoimenov, A., Koleva, R., Dimitrov, V., Tepeliev, Y., Lubenov, T. and Kroumova, J., "Satellite mapping of Bulgarian land cover - CORINE 2012 project," Forestry ideas, 20(2), 189-196 (2014).

[3] Avanesov, G., B. Bonev, F. Kempe, A. Bazilevsky, V. Boycheva, K. Chikov, M. Danz, D. Dimrtrov, T. Duxbury, P. Gromatikov, D. Halmann, J. Head,V. Heifets, V. Kolev, V. Kostenko, V. Kottsov, V. Krasavtsev, V. Krasikov, A. Krumov, A. Kuzmin, K. Losev, K. Lumme, D. Mishev, D. Mohlmann, K. Muinonen, V. Murav'ev, S. Murchie, B. Murray, W. Neumann, L. Paul, D. Petkov, I. Petuchova, W. Possel, B. Rebel, Yu. Shkuratov, S. Simeonov, B. Smith, A. Totev, V. Fedotov, G.-G. Weide, H. Zapfe, B. Zhukov and Ya. Ziman, "Television observations of Phobos," Nature, 341, 585-587 (1989).

[4] Kancheva, R., [State assessment of the soil-vegetation system using spectrometric data], PhD thesis, 142 (1999).

[5] Borisova, D., "Spectrometric measurements of granites and study of surface effects," Annual of the University of Mining and Geology, 46(I), 327-329 (2003).

[6] Kancheva, R., "Main principles in vegetation spectrometric studies," Annual of the University of Mining and Geology "St. Ivan Rilski", 46(I), 387-390 (2003).

[7] Borisova D. and Kancheva, R., "Spectroscopy of terrestrial and lunar basalt," Aerospace Research in Bulgaria, 2, 43-46 (2005).

[8] Borisova D., Nikolov, H. and Mircheva, M., "Soils cover estimation by remotely sensed data," Proceedings of National Conference with International Participation, 34-38 (2005).

[9] Borisova D., Nikolov, H. and Banushev, B., "In-situ and ex-situ measurements of igneous, sedimentary and metamorphic rocks for Earth observation data base complementation," Annual of the University of Mining and Geology, 52(I), 137-140 (2009).

[10]Borisova D., Kancheva, R. and Nikolov, H., "Remote sensing technique in soil monitoring in risk areas," Proceedings of International Conference "100 Years Soil Science in Bulgaria ", 1, $53-57$ (2011).

[11]Borisova, D., Banushev, B., Nikolov, H. and Petkov, D., "Field spectroscopy measurements of rocks in Earth observations," Annual of the University of Mining and Geology, 57(I), 133-136 (2014).

[12]Borisova, D. and Petkov, D., "Analysis of spectrometric optical data from different devices," Proc. SPIE 9245, 92450B-1-7 (2014).

[13]Borisova, D., Kancheva, R. and Nikolov, H., "Soil monitoring using spectral data," Proceedings of the 7th National Geophysical Conference with International Participation "Geophysics 2015”, S5-O3 (2015).

[14]Borisova, D., Banushev, B., Petkov, D., Nedkov, R. and Avetisyan, D., "Optical hyperspectral measurements of rocks and soils in Central Srednogorie, Bulgaria," Proc. SPIE 10444, 104441O-1-7 (2017).

[15]Ruby, J. and Fischer, R., "Spectral signatures database for remote sensing applications," Proc. SPIE 4816, 156163 (2002).

[16]Percival, J., Bosman, S., Potter, E., Peter, J., Laudadio, A., Abraham, A., Shiley, D. and Sherry, C., "Customized spectral libraries for effective mineral exploration: mining national mineral collections," Clays and Clay Minerals, 66(3), 297-314 (2018).

[17]Nedkov, R., "Orthogonal Transformation of Segmented Images from the Satellite Sentinel 2", Comptes rendus de l'Académie bulgare des Sciences (Proceedings of the Bulgarian Academy of Sciences), 70 (5), 687-692 (2017). 
[18]Nedkov R., "Normalized Differential Greenness Index For Vegetation Dynamics Assessment", Comptes rendus de l'Acad'emie bulgare des Sciences, 70 (8), 1143-1146 (2017).

[19]Banushev, B., [Sofia - Vlado Trtichkov - Batulijska - Redinska - Gara Bov. In: Practical Manual for Mineralogy and Petrography], "St. Ivan Rilski” Publishing House, Sofia, 23-28 (2012).

[20]Petkov, D., Nikolov, H. and Georgiev, G., "Thematically Oriented Multichannel Spectrometer (TOMS)," Aerospace Research in Bulgaria, 20, 51-54 (2005).

[21]Petkov, D., Krumov, A., Nikolov, H. and Georgiev, G., "Multichannel nadir spectrometer for thematically oriented remote sensing investigations," Proceedings of SES 2005, Varna, 227-231 (2005).

[22] ODbL, [Open Database License], https://opendatacommons.org/licenses/odb1/1.0/, March 2020, (2020). 